\title{
Suppression of cyclophosphamide induced diabetes development and pancreatic Th1 reactivity in NOD mice treated with the interleukin (IL)-12 antagonist IL-12(p40) 2
}

\author{
H . R othe ${ }^{1}$, R . M . O 'H ara J r. ${ }^{2}$, S. M artin ${ }^{1}$, H . Kolb ${ }^{1}$ \\ ${ }^{1}$ Diabetes Research Institute at the Heinrich-Heine University Düsseldorf, Düsseldorf, Germany \\ ${ }^{2}$ Genetics Institute, Inc., Cambridge, Massachusetts, USA
}

Summary The macrophage product interleukin (IL)12 is known to drive Th1 reactions in physiological and pathological immune responses. Here we report that treatment with the homodimeric IL-12p40 subunit, an antagonist of the bioactive IL-12p35/p40 heterodimer, suppresses diabetes development in cyclophosphamide-injected NOD mice. Female mice of 70 days old received cyclophosphamide $(250 \mathrm{mg} / \mathrm{kg})$ to accelerate and synchronize diabetes development, and daily injections of $1 \mu \mathrm{g} \mathrm{IL-12}(\mathrm{p} 40)_{2}$. While there was no delay of the first diabetes cases, the incidence of overt diabetes was significantly decreased in treated mice ( 46 vs $23 \%, p<0.05$ ). Analysis of mRNA expression in the pancreas showed that administration of the IL-12 antagonist had dampened interferongamma gene expression, decreased the ratio of
interferon-gamma/IL-10 mRNA levels and in parallel suppressed the expression of the inducible nitric oxide synthase. At the same time intra-islet infiltration was significantly decreased $(p<0.001)$. Interestingly, the administration of IL-12(p40) $)_{2}$ also affected IL-12 gene expression, by downregulation of p35 mRNA. We conclude that IL-12 p40 homodimer suppresses diabetes development in the NOD mouse by dampening islet inflammation via selective downregulation of Th1 type responses. The naturally occurring IL-12 antagonist IL-12(p40) $)_{2}$ represents a new and specific Th1 directed approach to prevent autoimmune diabetes. [Diabetologia (1997) 40: 641-646]

Keywords NOD mouse, IL-12 antagonist, Th1/Th2 balance, inducible NO synthase, insulitis.
The disease process in diabetes prone nonobese diabetic (NOD) mice can be accelerated by a single injection of cyclophosphamide (CY). Concomitantly, early peri-insular infiltration of islets progress to destructive intra-insulitis [1-3]. At the immunoregulatory level a shift from T-helper type 2 (Th2) towards Th1 type reactivity is noted, as evidenced by a marked increase of IFN- $\gamma$ gene expression [3-5]. We have reported previously that the increase in Th1

Received: 7 January 1997 and in revised form: 10 March 1997

Corresponding author: H. Rothe, PhD, Diabetes Research Institute, Auf'm Hennekamp 65, D-40225 Düsseldorf, Germany A bbreviations: HBSS, Hank's balanced salts solution; NOD, non-obese diabetic; CY, cyclophosphamide; IFN- $\gamma$, interferon-gamma; PSL, ${ }^{32} \mathrm{P}$ stimulated luminescence; iNOS, inducible nitric oxide synthase; RT-PCR, reverse transcriptase-polymerase chain reaction; FCS, fetal calf serum. reactivity in islets is preceded by a rise in IL-12 gene expression, suggesting that IL-12 mediates the accelerating effect of CY [6]. Indeed, the disease promoting effects of CY are suppressed in IL-12 knockout mice and daily injection of IL-12 to young NOD mice was found to expedite diabetes development $[7,8]$.

IL-12 is a $75 \mathrm{kDa}$ heterodimeric cytokine produced from macrophages and other antigen presenting cells. The p35 subunit is ubiquitously expressed in many cell types where the p40 subunit is inducible [9]. The production of biologically active recombinant IL-12 requires the coexpression of the IL-12 p40 and p35 subunits [10-12]. Although initially described as a cytokine activating spontaneously cytotoxic lymphocytes the significance of IL-12 lies in its effect on T-helper cells [12]. IL-12 conditions naive T-helper cells to differentiate along the Th1 pathway, and stimulates $\mathrm{Th} 0$ or $\mathrm{Th} 2$ cells to transiently produce 
interferon-gamma (IFN $\gamma)$ [12]. Furthermore, IL-12 is known to be involved in infectious and organ specific autoimmune diseases $[6,7,13,14]$. The $p 40$ subunit is able to form a homodimer, which has been shown to antagonize IL-12 activities in vitro and hence may reflect a natural suppressor of Th1 activation in vivo $[15,16]$. In our present study we examined the inhibitory effect of the IL-12 antagonist IL-12 (p40) $)_{2}$ on the development of the $\mathrm{CY}$ accelerated diabetes of the NOD mice in vivo.

\section{Materials and methods}

A nimals. Female NOD/Bom mice were purchased from Bomholtgard Breeding Centre (Ry, Denmark) at 9 weeks of age and maintained in our animal facility under conventional conditions with standard diet (Sniff, Soest, Germany) and tap water ad libitum (mean incidence: $0 \%$ at age 80 days, $>90 \%$ at age 250 days). One group of animals $(n=31)$ was treated daily with $0.5 \mu \mathrm{g}$ IL-12(p40) $2+2 \mu \mathrm{g}$ ovalbumin (OVA, grade VI; Sigma, Deisenhofen, Germany) daily for 3 days before treatment of the animals with $\mathrm{CY}$ and thereafter daily with $1 \mu \mathrm{g}$ IL-12 (p40) $)_{2}+2 \mu \mathrm{g}$ OVA for 4 weeks. The control animal group was treated with $2 \mu \mathrm{g}$ OVA only. All mice received CY $(250 \mathrm{mg} / \mathrm{kg}$ i.p.) at 70 days of age. Urinary glucose analysis was performed daily starting 8 days after CY treatment and hyperglycaemia was confirmed by blood glucose determination. Animals were regarded as diabetic when blood glucose levels were found to be above $16.7 \mathrm{mmol} / \mathrm{l}$ as determined by the hexokinase method. Groups of 5-6 normoglycaemic animals were killed before and 10 days after injection of CY. The later point of time is close to the onset of overt diabetes in a fraction of mice (Fig. 1). Mice were killed under anaesthesia, the pancreas was excised and cut in half longitudinally for histological and mRNA analysis. The principles of laboratory animal care were followed (NIH publication No. 85-23, revised 1985).

IL -12 homodimer. IL-12(p40) $)_{2}$ was generously provided by $\mathrm{E}$. Nickbarg (Genetics Institute, Cambridge, Mass., USA). Purified IL-12(p40) $)_{2}$ was prepared as described previously [16] and was essentially free (>98\%) of p40 monomer.

mRNA analysis. Total RNA was isolated from fresh pancreatic tissue by guanidinium thiocyanate-phenol-chloroform extraction [3]. Isolated RNA quality was verified by running a $1.2 \%$ agarose gel with $4 \%$ formaldehyde. All isolated RNA showed intact $18 \mathrm{~S}$ and $28 \mathrm{~S}$ rRNA bands without visible degradation of the mRNA, like total RNA of spleens which was always isolated in parallel. Determination and quantification of specific mRNA was performed by reverse transcriptase polymerase chain reaction (RT-PCR) as described elsewhere $[3,18]$. Specific primers for $\beta$-actin, IFN- $\gamma$, IL- 4 , IL-10 and TGF- $\beta$ were purchased from Clontech (Clontech Laboratories Inc., Palo Alto, Calif., USA). The specific primers for inducible nitric oxide synthase (iNOS), IL-12 p40 and IL-12 p35 were used as described elsewhere $[3,5]$. The first cycle of each PCR was started for $3 \mathrm{~min}$ at $95^{\circ} \mathrm{C}$ denaturation time. In the next cycles denaturation was performed for $1 \mathrm{~min}$. Primer annealing was done for $1 \mathrm{~min}$ at $60^{\circ} \mathrm{C}\left(\beta\right.$-actin, IFN- $\gamma$, IL-4, IL-10, TGF- $\beta$ ), $58^{\circ} \mathrm{C}$ (IL$12 \mathrm{p} 35), 55^{\circ} \mathrm{C}(\mathrm{IL}-12 \mathrm{p} 40)$ or $50^{\circ} \mathrm{C}$ (iNOS). The elongation steps were done at $72^{\circ} \mathrm{C}$ for $80 \mathrm{~s}$. ( $\beta$-actin, IFN- $\gamma$, IL-4, IL-10, TGF$\beta$ ), for $90 \mathrm{~s}$ (iNOS), $40 \mathrm{~s}$ (IL-12p35) or $30 \mathrm{~s}$ (IL-12p40). PCR products were subjected to electrophoresis on a $2 \%$ agarose

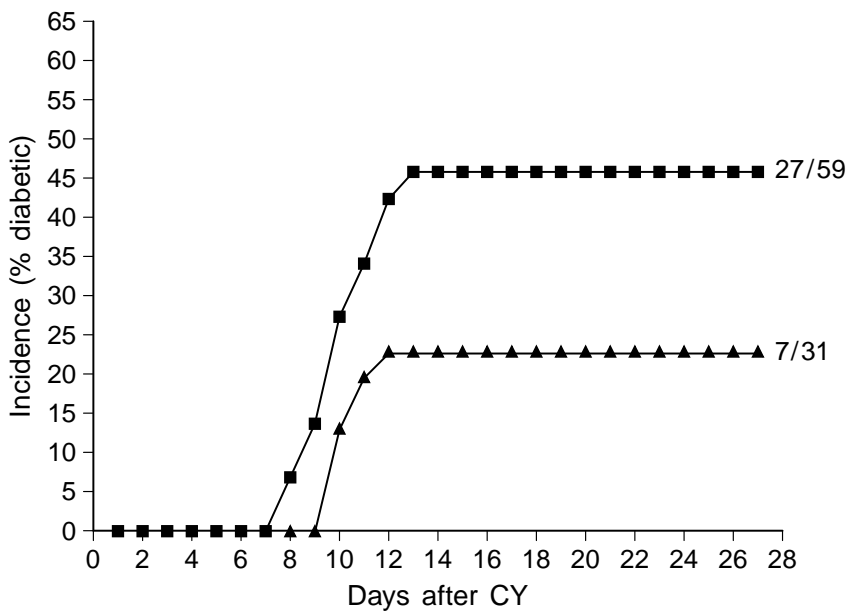

Fig. 1. Diabetes incidence of IL-12(p40)2 treated animals versus control group after CY treatment. Shown are the percentages of diabetic animals in the control group ( $\square$ ) and the IL$12(\mathrm{p} 40)_{2}$ treated group $(\boldsymbol{\Delta})$ after CY treatment

gel followed by hybridization with specific ${ }^{32} \mathrm{P}$ labelled probes binding at the sites between the primer sequences. Signals were quantified by measuring the ${ }^{32} \mathrm{P}$ stimulated luminescence (PSL) by a phosphorimager. Relative PSL of PCR products was calculated by normalization of the measured PSL to the strength of $\beta$-actin signal $[3,18]$. RT-PCR analysis of mRNAs was repeated by varying the cycle number for specific mRNA amplification $(\mathrm{n}=29,32,35)$ and for $\beta$-actin message amplification $(n=20,23,26,29,32)$. Relative PSL values generated in these experiments did not differ more than $25 \%$.

Isolation and stimulation of peritoneal macrophages. Peritoneal macrophages were isolated by lavage of the peritoneum with 4-ml ice-cold HBSS (Hank's balanced salt solution; Gibco, Heidelberg, Germany). The cells were washed three times with $10 \mathrm{ml}$ PBS (Gibco) and separated by adherence on FCS (fetal calf serum, Gibco) coated petri dishes $\left(37^{\circ} \mathrm{C}, 5 \% \mathrm{CO}_{2}\right)$. After $1 \mathrm{~h}$ the non-adherent cells were flushed off and the adherent cell population was detached by incubation for $7 \mathrm{~min}$ in ice-cold $\mathrm{Ca}^{2+}-\mathrm{Mg}^{2+}-$ free HBSS. The detached cells were washed three times in ice-cold PBS, resuspended in RPMI $1640+10 \%$ FCS at $10^{6} / \mathrm{ml}$, followed by culture in 12 -well microtiter wells. The cells were stimulated with $1 \mu \mathrm{g}$ lipopolysaccharide (LPS from Salmonella minnesota, Sigma) for 0, $24 \mathrm{~h}$.

Nitrite and TNF production by macrophages. Supernatants of the macrophage cultures were collected and nitrite levels were determined by the Griess method as described previously [19]. In the same supernatants TNF $\alpha$ levels were measured by a L929 bioassay [20].

$\mathrm{H}$ istology. Pancreatic tissue was snap frozen in liquid nitrogen and cryostat sections were stained with haematoxylin-eosin for evaluation of infiltrating immune cells by light microscopy. Analysis was done for all islets in different sections at intervals of $100 \mu \mathrm{m}$, yielding a total of at least 20 islets per animal. Three grades of infiltration were defined: grade 1: no periductular infiltrates or less than 5 immune cells peri- and intra-insular with or without periductular infiltrates; grade 2: periductular and peri-insular infiltrates with or without intra-islet infiltration of less than $20 \%$ of the islet area; grade 3 : intra-islet infiltration of more than $20 \%$ of the islet area. Slides were coded and insulitis grades rated independently by two observers. 

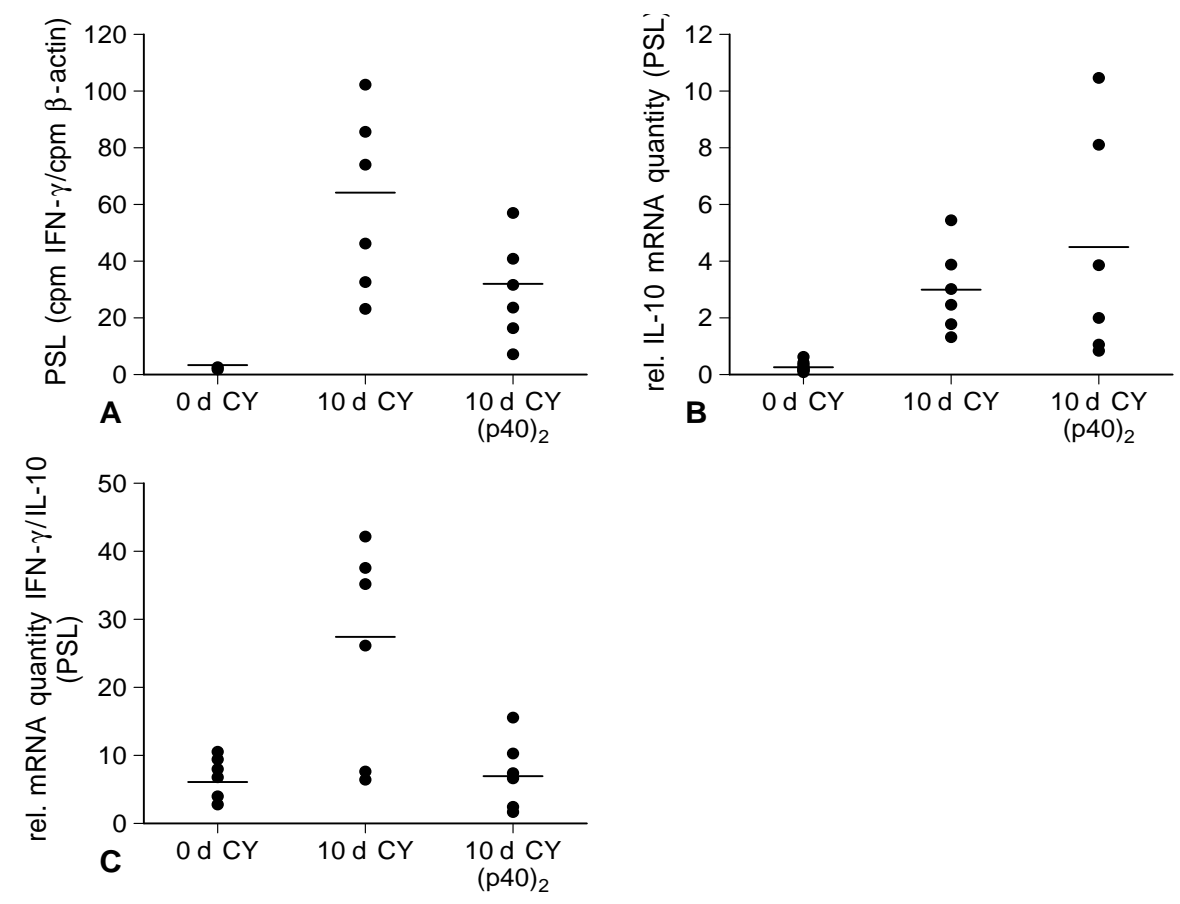

Fig. 2 A -C. RT-PCR analysis of Th1 cytokine IFN- $\gamma$ and Th2 cytokine IL-10 in pancreas of NOD mice before and 10 days after $\mathrm{CY} \pm 12(\mathrm{p} 40)_{2}$ treatment $\mathbf{A}$ : Relative quantities of RTPCR signal for IFN- $\gamma$ as determined by ${ }^{32} \mathrm{P}$ stimulated luminescence followed by normalization to the signals of RT-PCR of $\beta$-actin mRNA of individual mice. Single bars give mean values of each group. B: Relative quantities of RT-PCR signal for IL-10 calculated as described above. Single bars give mean values of each group. C: Ratios of relative mRNA quantities of RT-PCR signals for IFN- $\gamma / \mathrm{IL}-10$ of individual mice. The single bars give mean value of each group

Statistical analysis. Mean radioactive signals of RT-PCR products were compared by Wilcoxon U-test, Student $\cdot$ s t-test or rank correlation assay of Spearman (R). Statistical analysis for incidence of diabetes and degree of insulitis was performed by $\mathrm{chi}^{2}$-test.

\section{Results}

Treatment of NOD mice with CY induced overt diabetes in 27 of 59 mice (Fig. 1). All cases of diabetes occurred during days 8-13 after CY, demonstrating synchronization of the disease process. NOD mice treated daily with IL-12(p40) 2 showed suppression of diabetes incidence $(p<0.05$, Fig. 1$)$. There was no delay of diabetes development in the IL-12(p40) 2 treated mice compared to the control group.

Prior to CY administration NOD mice were devoid of insulitis in the majority of islets (Table 1). Substantial progression of insulitis was seen 10 days after CY treatment in normoglycaemic mice. Nearly all islets exhibited an advanced insulitis grade with intra-islet infiltration $(97 \%, p<0.0001$ compared to day 0$)$. In the IL-12(p40), treated group progression of insulitis towards intrainsular infiltration was also noted, but it was less pronounced 10 days after CY treatment, with $25 \%$ rather than $3 \%$ of islets with grades $1-2(p<0.001$ compared to animals treated with CY alone, Table 1).

Analysis of the cytokine mRNA expression pattern in these animals showed significant differences between the normoglycaemic IL-12(p40) $)_{2}$ treated and control animals. The CY-treated control animals showed upregulated gene expression in the Th1 specific cytokine IFN- $\gamma$. Treatment with IL-12(p40) dampened the rise in IFN- $\gamma$ mRNA levels $(p<0.05$, Fig. 2A). Gene expression of the Th2 cytokine IL-10

Table 1. Islet infiltration grades

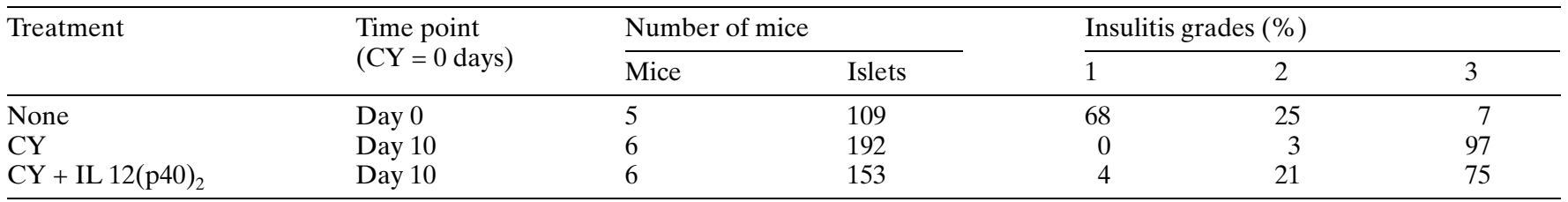

Islet infiltration grades were analysed by eosin-haematoxylin staining of snap frozen pancreata 


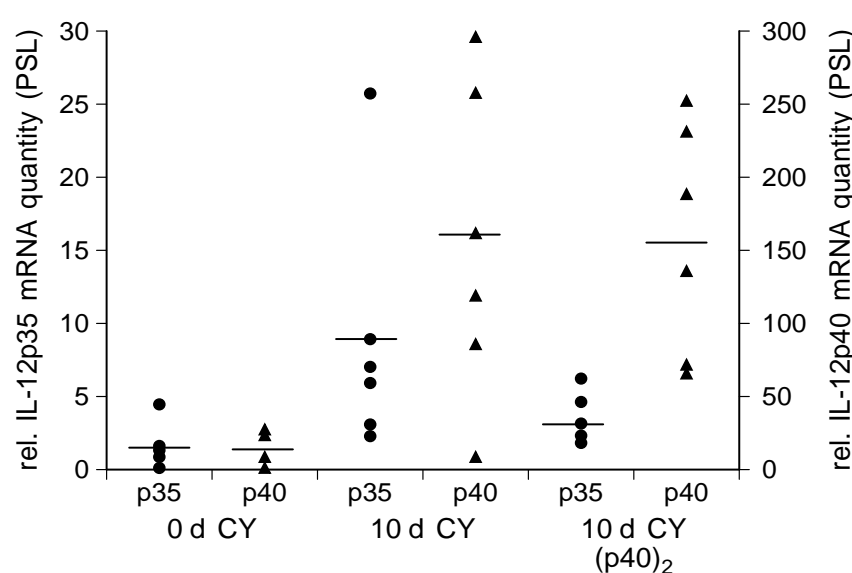

Fig. 3. RT-PCR analysis of IL-12 p40 and p35 subunits in pancreas of NOD mice before and 10 days after CY $\pm 12(\mathrm{p} 40)_{2}$ treatment. Shown are relative quantities of RT-PCR signal for p40 ( $\boldsymbol{\nabla})$ and p35 (O) as determined by ${ }^{32} \mathrm{P}$ stimulated luminescence followed by normalization to signals of RT-PCR of $\beta$-actin mRNA of individual mice. Single bars give mean values of each group

was also induced by CY but mean mRNA levels were not significantly affected by administration with IL12 p40 homodimer. The most striking effects were noted for the ratio of IFN- $\gamma$ compared to IL-10 mRNA levels. Treatment with IL-12(p40 $)_{2}$ strongly decreased Th1/Th2 mRNA ratios (Fig. $2 \mathrm{C}, \mathrm{p}<0.01$ ).

The analysis of IL-12p35 and p40 mRNA is shown in Figure 3. CY induced a fivefold increase of IL12 p35 and an eightfold increase of IL-12p40 mRNA. Concomitant administration of the IL-12 antagonist decreased p35 mRNA levels $(p<0.05)$ but did not affect p40 mRNA levels. Next, the ratio of IL-12p40 compared to p35 mRNA levels of individual animals

Fig. 4 A , B . RT-PCR analysis of iNOS in the pancreas of NOD mice before and 10 days after $\mathrm{CY} \pm 12(\mathrm{p} 40)_{2}$ treatment. A : Relative quantities of RT-PCR signal for iNOS as determined by ${ }^{32} \mathrm{P}$ stimulated luminescence followed by normalization to the signals of RT-PCR of $\beta$-actin mRNA of individual mice. Single bars give the mean values of each group. B : Correlation of individual iNOS and IFN- $\gamma / \mathrm{IL}-10 \mathrm{mRNA}$ expression in pancreas of NOD mice. Shown are individual data for NOD mice was calculated. The group treated with IL-12 antagonist had a lower $\mathrm{p} 35 / \mathrm{p} 40$ ratio $(\mathrm{p}<0.05)$.

We also examined the mRNA expression of the iNOS as a parameter closely associated with betacell destruction $[3,17]$. INOS mRNA expression increased after CY treatment in both animal groups, but there was significantly less iNOS mRNA expression in the IL-12(p40) 2 treated animal group (Fig. 4A, p < 0.05). Animals with high iNOS expression also showed a high ratio of Th1 over Th2 cytokine expression (Fig.4B). The correlation between iNOS mRNA levels and the ratio IFN- $\gamma / \mathrm{IL}-$ 10 mRNA was calculated as $R=0.98, p<0.05$.

Finally, we tested wether administration of IL$12(\mathrm{p} 40)_{2}$ had any general effects on macrophage function. Peritoneal macrophages were harvested 10 days after $\mathrm{CY}$ treatment and challenged in vitro with $1 \mu \mathrm{g}$ LPS $/ \mathrm{ml}$. Macrophages from NOD mice which had received CY plus IL-12(p40) $)_{2}$ responded similarly to those from the $\mathrm{CY}$ control group with substantial nitrite production $\left(2.9 \pm 4.8 \mu \mathrm{mol} / 1 \mathrm{NO}_{2}^{-}\right.$ [CY] vs $\left.2.9 \pm 4.8 \mu \mathrm{mol} / \mathrm{INO}_{2}^{-}\left[\mathrm{CY}+(\mathrm{p} 40)_{2}\right], \mathrm{n}=6\right)$ and $\mathrm{TNF} \alpha$ release $(50.8 \pm 25.8 \mathrm{U}[\mathrm{CY}]$ vs $40.0 \pm 21.2$ $\mathrm{U}$ TNF $\left.\left[\mathrm{CY}+(\mathrm{p} 40)_{2}\right], \mathrm{n}=6\right)$ at $24 \mathrm{~h}$.

\section{Discussion}

Administration of IL-12(p40) $)_{2}$ significantly decreased the incidence of CY-induced diabetes. It is probable that this effect is due to the inhibitory effect of the p40 homodimer on IL-12 functions as shown in vitro [15]. During preparation of this manuscript, parallel work by Trembleau et al. [21] has been published in abstract form which also describes an inhibitory effect of IL-12(p40) $)_{2}$ on the disease process in NOD mice. IL-12(p40) $)_{2}$ acts as a specific antagonist by binding to the IL-12 receptor without inducing appropriate signals $[16,22]$. If exogenous IL-12(p40) ${ }_{2}$ exhibited similar properties in vivo, effects on IL-12 driven IFN- $\gamma$ production and the Th1/Th 2 cytokine balance are to be expected. Previous studies linked a shift towards Th1 dominated insulitis with progression from benign towards destructive insulitis and subsequent diabetes onset. We therefore analysed
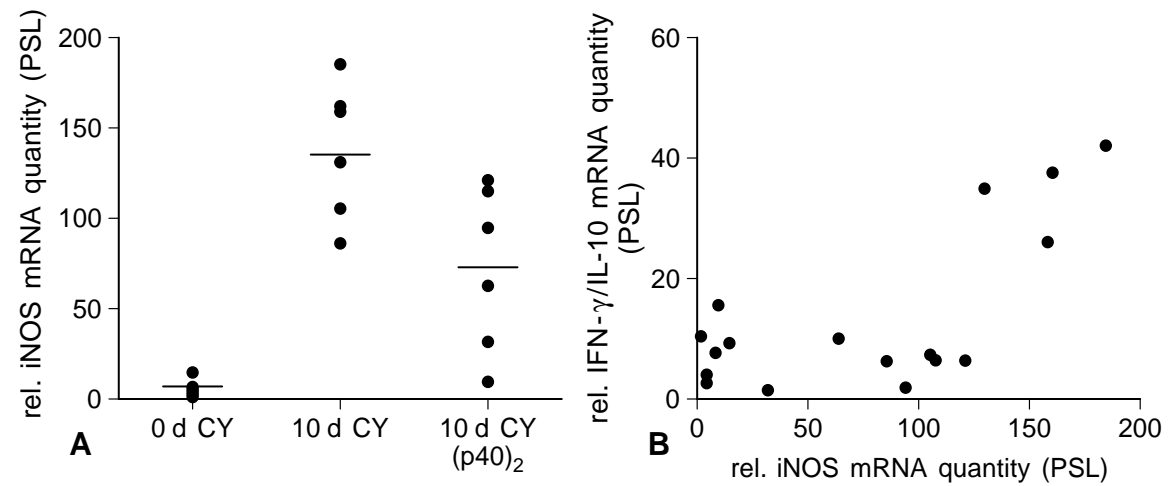
mice before and after $\mathrm{CY}$-accelerated progression towards Th1 insulitis. Indeed, we observed less IFN- $\gamma$ gene expression and a decreased IFN- $\gamma /$ IL10 mRNA ratio in the pancreas of NOD mice receiving injections of $\mathrm{p} 40$ homodimer in addition to CY.

Cytokine gene expression was analysed in total pancreas RNA because islet isolation in our hands introduces a bias due to poor islet yield in animals with advanced stages of insulitis and the preferential loss of periductular and peri-insular over intra-islet leukocytes during the isolation procedure. Previous studies have shown a close correlation between pancreatic mRNA levels and immunostaining of cytokines in islet sections [3]. In addition, we observed a close correlation between cytokine mRNA levels in total pancreas with the mean insulitis score in individual animals [18] in another animal model of spontanous diabetes development, the BioBreeding rat.

We conclude that exogenous IL-12(p40) $)_{2}$ interfered with activation of Th1 immune reactivity in the pancreas of CY-treated NOD mice, leading to dampening of Th1-dependent destructive insulitis. The conclusion concurs with results of semiquantitative grading of insulitis which shows a significant decrease of intra-islet infiltration in mice receiving IL$12(\mathrm{p} 40)_{2}$.

The lesser aggressiveness of the insulitis process in mice treated with the IL-12 antagonist is also recognizeable from a significantly decreased expression of iNOS mRNA. INOS mRNA is induced in macrophages, endothelial cells and beta cells by inflammatory cytokines such as IFN- $\gamma$, IL- 1 and TNFo, while Th2 cytokines are inhibitory [23-25]. A close correlation between pancreatic iNOS mRNA levels and destructive intra-islet infiltration has been reported by our group $[3,18]$. An interrelationship between the cytokine network and iNOS gene expression is demonstrated here by a significant correlation of individual iNOS mRNA levels with the IFN- $\gamma /$ IL10 mRNA ratio in pancreatic RNA. A causal relationship between IFN- $\gamma / \mathrm{IL}-10$ mRNA ratio and iNOS expression seems probable. Studies in vitro and in vivo have shown that IFN- $\gamma$ induces iNOS expression while IL-10 is suppressive [26,27]. Nitric oxide is regulated as a mediator of beta-cell destruction in rodent models of type 1 diabetes [28, 29]. In addition, iNOS expression is a marker of macrophage activation. Taken together, the decreased expression of iNOS mRNA in the pancreas of NOD mice receiving IL-12(p40) ${ }_{2}$ indicates a dampening of the diabetogenic inflammatory process.

Interestingly, the administration of IL-12(p40) also acted back on IL-12 gene expression. While levels of p40 mRNA remained unaffected there was significant suppression of $\mathrm{p} 35$ gene expression. The $\mathrm{p} 35$ subunit of the bioactive heterodimer appears to mediate much of the signalling in terms of inducing IFN- $\gamma$ production in IL-12 receptor positive Th1 or
Th0 cells [30, 31]. Hence, the downregulation of p35 message in reponse to IL-12(p40) $)_{2}$ treatment indicates a decrease of bioactive IL-12 in NOD mouse pancreas. This regulatory action of the p40 homodimer on p35 gene expression may result from a direct effect on macrophages or may be a consequence of decreased Th1 reactivity and the resulting lower IFN- $\gamma / \mathrm{IL}-10$ ratio. IFN- $\gamma$ is a potent inducer, IL-10 is a suppressor of IL-12 production [32]. However, IL10 has been reported to suppress both p35 and p40 gene transcription [33], which has not been observed here. We conclude that the IL-12 antagonist not only competes with bioactive IL-12 for Th1 cell activation but also suppresses further release of IL-12 inhibiting IL-12p35 gene transcription.

Our studies render an in vivo role of the p40 homodimer in regulating IL-12 bioactivity and Th1 responses possible. Further support has come from a pilot trial of IL-12(p40) $)_{2}$ treatment in collagen arthritis of mice, where a delay of clinical symptoms and a decrease of disease incidence was noted [34]. A role for IL-12(p40) $)_{2}$ as a natural antagonist of IL-12 in vivo is also supported by reports that $\mathrm{p} 40$ is produced in excess over IL-12 [32-35] and for longer periods than bioactive IL-12 is demonstrable [36, 37]. In situ hybridization of spleens of LPS-injected mice showed that most of the p35 and p40 mRNA is localized in different areas [38]. Naturally occurring p40 homodimer has been purified and shown to inhibit IL-12induced T-cell proliferation.

In conclusion, we have shown that exogenous IL$12(\mathrm{p} 40)_{2}$ represents a new and specific approach to interfere with the development of IL-12 dependent autoimmune type 1 diabetes. Since IL-12(p40) $)_{2}$ also occurs naturally, treatment with this IL-12 antagonist probably makes use of physiological feedback mechanisms to restrict Th1 reactivities. Furthermore, the decreased expression of iNOS in the pancreata of IL-12(p40) $)_{2}$ treated mice indicates a lower activation stage of macrophages and other inflammatory cells, which will promote beta-cell survival.

A cknowledgements. We thank Michael Blendow for excellent technical assistance. This work was supported by the Bundesminister für Gesundheit, by the Minister für Forschung und Wissenschaft des Landes Nordrhein-Westfalen and by the Deutsche Forschungsgemeinschaft. We thank Prof. Dr. F.A Gries for continuous support of our scientific work.

\section{References}

1. Harada M, Makino S (1984) Promotion of spontaneous diabetes in non-obese diabetes-prone mice by cyclophosphamide. Diabetologia 27: 604-606

2. Yasunami R, Bach J-F (1988) Anti-suppressor effect of cyclophosphamide on the development of spontaneous diabetes in NOD mice. Eur J Immunol 18: 481-484

3. Rothe H, Faust H, Schade U et al. (1994) Acceleration of diabetes development in NOD mice by cyclophosphamide 
is associated with a shift from IL-4 to IFN-gamma production and with enhanced expression of inducible NO-synthase in pancreatic lesions. Diabetologia 37: 1154-1158

4. Campell IL, Kay TWH, Oxbrow L, Harrison LC (1991) Essential role for interferon- gamma and interleukin-6 in autoimmune insulin-dependent diabetes in NOD/Wehi mice. J Clin Invest 87: 739-742

5. Rabinovitch A (1994) Immunoregulatory and cytokine imbalances in the pathogenesis of IDDM. Diabetes 43: 613621

6. Rothe H, Burkart V, Faust A, Kolb H (1996) Interleukin-12 gene expression is associated with rapid diabetes development in NOD mice. Diabetologia 39: 119-122

7. Trembleau S, Penna G, Bosi E, Mortara A, Gately MK, Adorini L. (1995) Interleukin-12 administration induces T helper type I cells and accelerates autoimmune diabetes in NOD mice. J Exp Med 181: 817-821

8. O'Hara RM, Henderson SL, Nagelin A (1996) Prevention of a Th1 disease by a Th1 cytokine: IL-12 and diabetes in NOD mice. In: Lotze MT, Trinchieri G, Gately M, Wolf S (eds) Interleukin 12: cellular and molecular immunology of an important regulatory cytokine. Ann N Y Acad Sci 759: 241-249

9. Trinchieri G (1994) Interleukin-12: a cytokine produced by antigen-presenting cells with immunregulatory functions in the generation of T-helper cells type I and cytotoxic lymphocytes. Blood 48: 4008-4027

10. Wong HL, Wilson DE, Jenson JC, Familletti PC, Stremlo DL, Gately MK (1988) Characterizion of a factor(s) which synergizes with recombinant interleukin 2 in promoting allogeneic human cytolytic T-lymphocyte responses in vitro. Cell Immunol 111: 39-54

11. Kobayashi M, Fitz L, Ryan M et al. (1989) Identification and purification of natural killer cell stimulatory factor (NKSF) a cytokine with multiple biological effects on human lymphocytes. J Exp Med 170: 827-845

12. Burunda MJ (1994) Interleukin-12. J Leukoc Biol 55: 280 288

13. Harding FA, McArtur JG, Gross JA, Raulet DH, Allison JP (1992) CD28-mediated signalling co-stimulates murine $\mathrm{T}$ cells and prevents induction of anergy in T-cell clones. Nature 356: 607-609

14. Vieira LQ, Hondowicz BD, Alfonso LCC, Wysocka M, Trinchieri G, Scott P(1994) Infection with Leishmania major induces IL-12 production in vivo. Immunol Lett 40: 157-161

15. Mattner F, Fischer S, Guckes S, Jin S, Kaulen H, Rüde E, Germann T (1993) The interleukin-12 p40 subunit specifically inhibits effects of the interleukin-12 heterodimer. Eur J Immunol 23: 2203-2208

16. Gillessen S, Carvajal D, Ling P et al. (1995) Mouse interleukin-12 p40 homodimer: a potent IL-12 antagonist. Eur J Immunol 25: 200-206

17. Nickbarg EB, Vath JE, Pittman DP, Leonard JE, Walburger KE, Bund MD (1995) Structural characterization of the recombinant 440 heavy chain subunit monomer and homodimer of murine IL-12. Bioorg Chem 23: 380-396

18. Kolb H, Wötz-Pargenstert U, Kleemann R, Rothe H, Rowsell P, Scott FW (1996) Cytokine gene expression in BB rat pancreas: natural course and impact of bacterial vaccines. Diabetologia 39: 1448-1454

19. Wood, KS, Buga, GM, Byrns RE, Ignarro LJ (1990)Vascular smooth muscle-derived relaxing factor (MDRF) and its close similarity to nitric oxide. Biochem Biophys Res Commun 170: 80-88

20. Unglaub R, Maxeiner B, Thoma B, Pfizenmeier K, Scheurich $\mathrm{P}$ (1987) Downregulation of tumor necrosis factor sensitivity via modulation of TNF binding capacity by proteinase C activators. J Exp Med 166: 1788-1797
21. Trembleau S, Penna G, Gregori L, Adorini L (1996) Favoring the development of the Th2 cells by IL-12 antagonist administration prevents but does not treat IDDM. Autoimmunity 24:A118 (Abstract)

22. Ling P, Garely MK, Gubler U et al. (1995) Human IL-12 p40 homodimer binds to the IL-12 receptor but does not mediate biologic activity. J Immunol 154: 116-127

23. Ding A, Nathan CF, Stuehr DJ (1988) Release of reactive nitrogen intermediates and reactive oxigen intermediates from mouse peritoneal macrophages: comparison of activating cytokines and evidence of independent production. J Immunol 139: 518-523

24. Southern C, Schulster D, Green IC (1990) Inhibition of insulin secretion by interleukin- $1 \beta$ and tumor necrosis factor $\alpha$ via L-arginine-dependent nitric oxide generating mechanism. FEBS Letters 276: 42-44

25. Suschek C, Rothe H, Fehsel K, Enczmann J, Kolb-Bachofen V (1993) Induction of a macrophage-like nitric oxide synthase in cultured rat aortic endothelial cells. J Immunol 151: 3283-3291

26. Bogdan C, Vodovotz Y, Nathan C (1991) Macrophage deactivation by interleukin 10. J Exp Med 174: 1549-1555

27. Fiorentino DF, Zlotnik A, Vieira Pet al. (1991) IL-10 acts on the antigen-presenting cell to inhibit cytokine production by Th1 cells. J Immunol 146: 3444-3451

28. Corbett JA, Mikhael A, Shimizu J et al. (1993) Nitric oxide production in islets from non-obese diabetic mice: aminoguanidine-sensitive and resistant stages in the immunological diabetic process. Proc Natl Acad Sci USA 90: 8992-8995

29. Kolb H, Kolb-Bachofen V (1992) Type 1 (insulin-dependent) diabetes mellitus and nitric oxide. Diabetologia 35: 796-797

30. Snijders A, Hilkens CMU, Kraan TCTMV, Engel M, Aarden LA, Kapsenberg ML (1996) Regulation of bioactive IL-12 production in lipopolysaccharide-stimulated human monocytes is determined by expression of the p35 subunit. J Immunol 156: 1207-1212

31. Hayes MP, Wang JH, Norcoss MA (1995) Regulation of interleukin-12 expression in human monocytes: selective priming by interferon-gamma of lipopolysaccharide inducible p35 and p40 genes. Blood 86: 646-650

32. Trinchieri G (1993) Interleukin-12 and its role in the generation of Th1 cells. Immunol Today 14: 335-337

33. Dandrea A, Asteamezaga M, Valiante NM, Ma XJ, Kubin M, Trinchieri G (1993) Interleukin-10 (IL-10) inhibits human lymphocyte interferon-gamma production by suppressing natural killer stimulatory factor/IL-12 synthesis in accessory cells. J Exp Med 178: 1041-1048

34. Germann T (1996) The effects of IL-12 and IL-12 inhibitors in the collagen induced arthritis model. In: MT Lotze, G Trinchieri, M Gately, S Wolff (eds) Interleukin-12: cellular and molecular immunology of an important regulatory cytokine. New York Academy of Science Press, New York, USA pp 227-240

35. Heinzel FP, Rerko RM, Ling P, Hakimi J, Schoenhaut DS (1994) Interleukin-12 is produced in vivo during endotoxemia and stimulates synthesis of gamma interferon. Infect Immun 62: 4244-4249

36. Wysocka M, Kubin M, Vieira LQ et al. (1995) Interleukin12 is required for interferon-gamma production and lethality in lipopolysaccharide-induced hoch in mice. Eur J Immunol 25: 672-676

37. Zhang M, Gately MK, Wang E et al. (1994) Interleukin-12 at the site of disease in tuberculosis. J Clin Invest 93: 1733-1938

38. Bette M, Jin SC, Germann T, Schafer MKH, Weihe E, Rüde E, Fleischer B (1994) Differential expression of mRNA encoding interleukin-12 p35 and p40 in situ. Eur J Immunol 24: 2435-2440 